\title{
Mechanism of Corrosion in Porcelain Insulators and Its Effect on the Lifetime
}

\author{
Taeyong Kim ${ }^{1}{ }^{\oplus}$, Youn-Jung Lee ${ }^{1}$, Simpy Sanyal ${ }^{1}$, Jung-Wook Woo ${ }^{2}$, In-Hyuk Choi ${ }^{2, *}$ and \\ Junsin $\mathrm{Yi}^{1}{ }^{1, *}$ \\ 1 College of Information and Communication Engineering, Sungkyunkwan University, Suwon, Gyeonggi-Do \\ 16419, Korea; absolutely@skku.edu (T.K.); younjlee@skku.edu (Y.-J.L.); Sanyalsimpy@gmail.com (S.S.) \\ 2 KEPCO Research Institute, Daejeon 34056, Korea; mark.woo@kepco.co.kr \\ * Correspondence: inhyukchoi@kepco.co.kr (I.-H.C.); junsin@skku.edu (J.Y.); Tel.: +82-31-290-7139 (J.Y.)
}

Received: 2 October 2019; Accepted: 31 December 2019; Published: 6 January 2020

\begin{abstract}
Porcelain insulators should be exchanged periodically, but their lifetime is not clearly defined. One factor that affects service life is corrosion occurring at the pin and cap-each of which is made of iron with a zinc coating. A number of porcelain insulators used for different lengths of time in different locations are gathered, and the corrosion mechanisms of the cap and pin are investigated. The corrosion mechanism of the cap is mainly galvanic corrosion while that of the pin is primarily electrolytic and crevice corrosion as well as galvanic corrosion. Although time is an important factor in corrosion, it is found that corrosion is more influenced by geographical factors. Since the amount of acid rain and sea salt — each of which causes rapid rusting - is dependent on geographical factors, the location of where porcelain insulators are installed should be considered when predicting their lifetime. Theoretically, if there is only galvanic corrosion occurring, the expected lifetime is 56 years in an industrial area when the zinc coating has a thickness of $75 \mu \mathrm{m}$. Previous articles dealing with aging have predicted the maximum lifetime of porcelain insulators used in Korea to be approximately 30 years. To prolong the lifetime of porcelain insulators, further study is required in which the use of zinc alternatives, or waterproof coatings (in addition to the zinc coating), could be examined.
\end{abstract}

Keywords: porcelain insulator; lifetime; corrosion; service time

\section{Introduction}

Insulators are used to mechanically support and to electrically isolate transmission lines from the grounded tower structure. There are three main types of insulators: glass, polymer, and porcelain. The insulator occupies a small portion (5-8\%) of the cost of installing overhead transmission lines, but it accounts for more than $50 \%$ of the maintenance cost in the event of failure and plays an important role in determining the reliability of the line [1]. Thus, it is important to replace insulators at the right time. Porcelain insulators are mainly composed of three parts: porcelain, metal (cap and pin), and cement (which bonds the porcelain and metal parts). The factors that affect the lifetime of porcelain insulators are the deterioration of the ceramic, degradation of the cement, and corrosion of the metal parts. In this paper, the corrosion mechanisms in the cap and pin of porcelain insulators are described and the effects of corrosion on the lifetime of the insulators are discussed. The corrosion mechanism of the cap is mainly galvanic corrosion, while that of the pin is primarily electrolytic and crevice corrosion, as well as galvanic corrosion [2,3]. Consequently, dependency of corrosion on geographical factors has also been presented while focusing on preventive techniques. Due to this, used porcelain insulators were gathered from different regions in Korea. The dependence of corrosion on geographical features is also analyzed. Furthermore, $154 \mathrm{kV}$ porcelain insulators of different service durations in different areas were gathered. Figure 1 shows the locations of cities in Korea where used porcelain insulators were 
gathered. The corrosion states of these samples were characterized depending on the geographical features and service duration.

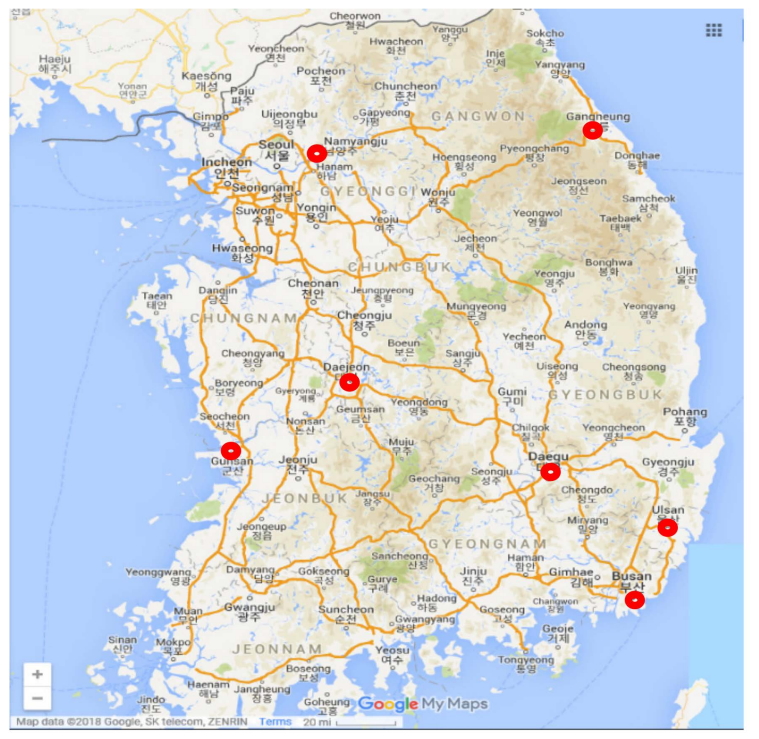

Figure 1. Cities where used porcelain insulators were gathered.

\section{Experiment}

Porcelain insulator samples are collected from various power transmission lines of South Korea with 25,000 pounds operated at $154 \mathrm{kV}$. These are discarded from utility systems to access the condition of similar samples. It has been categorized into different pollution levels. In South Korea, pollution grades are divided into A, B, C, and D in ascending order of pollution level. This is classified as the distance from the coast and Class $\mathrm{D}$ is the most polluted. Table 1 depicts relevant specifications of samples collected. The dependence of corrosion on geographical features are analyzed on $154 \mathrm{kV}$ porcelain insulators. The corrosion mechanism of the cap is mainly galvanic corrosion while that of the pin is primarily electrolytic and crevice corrosion as well as galvanic corrosion. Figure 2 shows samples of insulators used for different lengths of time. For the insulator used in Daejeon for 38 years, the cap was only slightly rusted but the pin corrosion was advanced. For the insulator used in Gangneung for 40 years, although there were numerous scratches on the cap, the pin showed little rust. For the insulator used in Dae-gu for 48 years, there was substantial rust on one side of the cap and a smaller amount at the pin. For the insulator used in Namyangju for 51 years, corrosion of the cap and pin was not very severe. Based on the observation, it was found that the degree of corrosion and rate of corrosion were more dependent on where the insulators were installed rather than the service time of the insulator. The factors required to calculate the rate of corrosion are decreased in metal weight during the reference time period, density of the metal, total initial surface area of the metal, and the length of the service period [4-6]. Therefore, samples in service for the same duration-38 years-but in different locations were compared. The effect of geographical location on corrosion and corrosion rate-i.e., the environmental conditions-was studied. 
Table 1. Samples.

\begin{tabular}{cccc}
\hline Years in Service & Region & Pollution Level & Number of Samples \\
\hline 38 & Daejeon & A & 176 \\
38 & Ulsan & B & 147 \\
38 & Busan & C & 147 \\
38 & Gunsan & C & 120 \\
40 & Gangneung & A & 273 \\
42 & Gyeongnam & C & 200 \\
47 & Gunsan & C & 120 \\
48 & Dae-gu & A & 441 \\
49 & Namyangju & clean area & 200 \\
51 & Namyangju & clean area & 200 \\
\hline
\end{tabular}
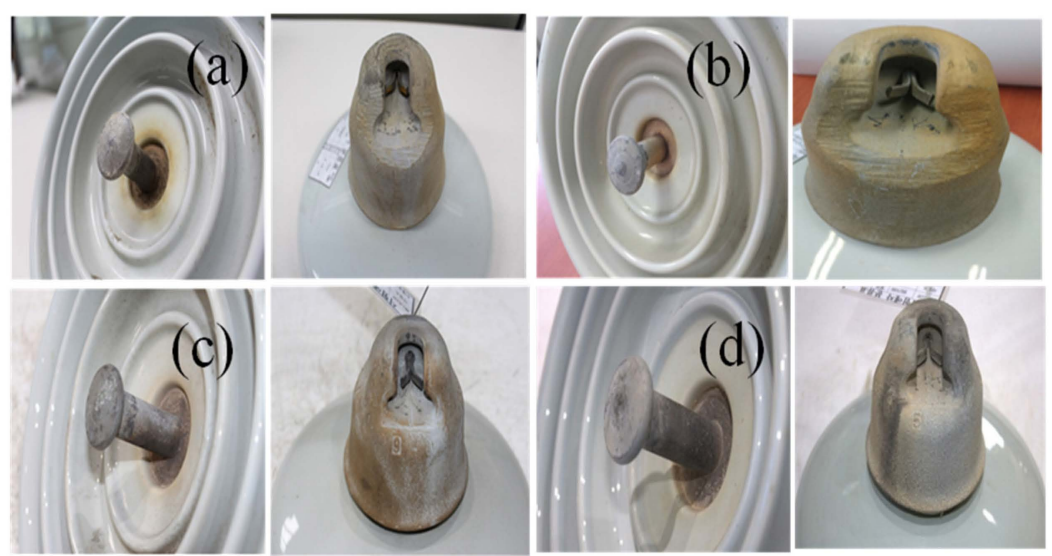

Figure 2. Appearance of pins and caps of porcelain insulators used for (a) 38 years in Daejeon, (b) 40 years in Gangneung, (c) 48 years in Dae-gu, and (d) 51 years in Namyangju.

\section{Results and Discussion}

Figure 3 shows a cross-section of a porcelain insulator. The cap and pin are made of iron, which is easily corroded when it comes in contact with water and oxygen. The following describes the rust generation process.

(A) Iron oxidation:

$$
\mathrm{Fe} \rightarrow \mathrm{Fe}^{2+}+2 \mathrm{e}^{-} \mathrm{Fe}^{2+} \rightarrow \mathrm{Fe}^{3+}+\mathrm{e}^{-}
$$

(B) Oxygen reduction:

$$
\mathrm{O}_{2}+2 \mathrm{H}_{2} \mathrm{O}+4 \mathrm{e}^{-} \rightarrow 4 \mathrm{OH}^{-}
$$

(C) Red color formation:

$$
2 \mathrm{Fe}^{3+}+6 \mathrm{OH}^{-} \rightarrow \mathrm{Fe}_{2} \mathrm{O}_{3} \cdot 3 \mathrm{H}_{2} \mathrm{O} \text { (rust) }
$$

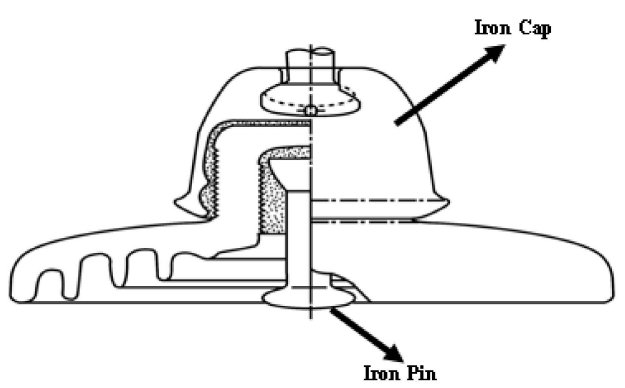

Figure 3. Cross-section of a porcelain insulator. 
For the cap, the main corrosion mechanism is galvanic corrosion. However, galvanic, electrolytic, and crevice corrosion may occur at the pin.

\subsection{Galvanic Corrosion}

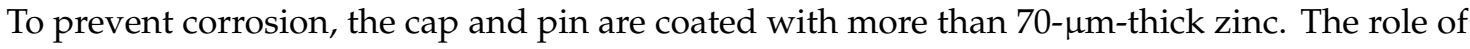
zinc is galvanic protection and oxide film formation. Galvanic corrosion occurs when two different metals in an electrolyte come into contact with each other, which causes a current to flow between them. As a result, the corrosion of metals with high corrosion resistance (cathode) is suppressed and the corrosion of metals with high activity (anode) is promoted. When iron and zinc are in contact, if the iron is exposed due to a defect or scratch, it gradually becomes cathodic.

$$
\mathrm{Fe}^{3+}+\mathrm{e}^{-} \rightarrow \mathrm{Fe}^{2+}
$$

Meanwhile, the $\mathrm{Zn}$ becomes increasingly anodic.

$$
\mathrm{Zn}^{2+}+2 \mathrm{e}^{-} \rightarrow \mathrm{Zn}
$$

Therefore, the iron is protected until the zinc is fully corroded by water and oxygen. In a neutral state where oxygen is dissolved, zinc first causes the following corrosion reactions.

Anode reaction:

$$
\mathrm{Zn} \rightarrow \mathrm{Zn}^{2+}+2 \mathrm{e}^{-}
$$

Cathode reaction:

$$
1 / 2 \mathrm{O}_{2}+\mathrm{H}_{2} \mathrm{O}+2 \mathrm{e}^{-} \rightarrow 2 \mathrm{OH}^{-}
$$

$\mathrm{Zn}(\mathrm{OH})_{2}$, which is not soluble in water, is formed by binding a zinc ion $\left(\mathrm{Zn}^{2+}\right)$, which is generated in the anode reaction, and hydroxide ion $\left(\mathrm{OH}^{-}\right)$, which is generated in the cathode reaction. This zinc hydroxide film is stable in the $\mathrm{pH}$ range of 6 to 12 and acts as a barrier against the diffusion of oxygen, which suppresses the corrosion of zinc. Figure 4 shows the $\mathrm{PH}$ dependence of the zinc corrosion rate. In an actual fresh water environment, a complicated surface film-composed of zinc oxide $(\mathrm{ZnO})$ and basic carbon zinc $\left(2 \mathrm{ZnCO}_{3} \bullet 3 \mathrm{Zn}(\mathrm{OH})_{2}\right)$ - as well as zinc hydroxide are formed by the action of various dissolved ions. The corrosion rate of zinc in distilled water shows a relatively high value of approximately $0.25 \mathrm{~mm} / \mathrm{y}$ at a $\mathrm{pH}$ of 7 . However, the surface coating formed in actual fresh water serves as a protective film for suppressing the zinc corrosion rate to a much lower level $[7,8]$.

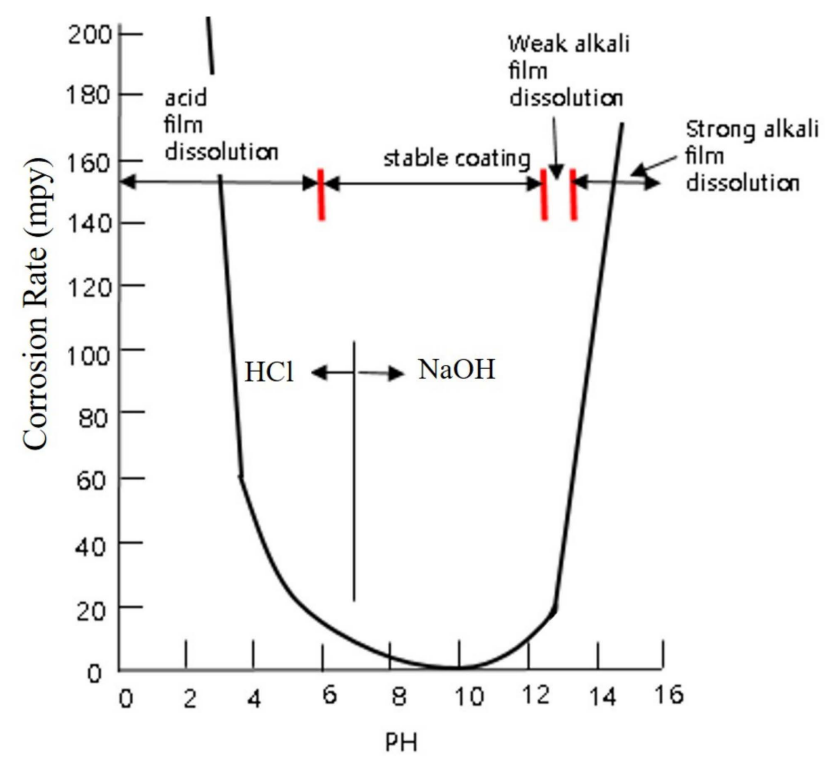

Figure 4. Zinc corrosion rate dependence on $\mathrm{pH}$. 
The movement of oxygen to the zinc surface is a very important factor in the film formation. A sufficient supply of oxygen to the zinc surface is required to maintain the film. If oxygen is not sufficiently transferred to the zinc surface, a defect presents in the coating and the zinc formula begins. The surrounding area covered with the film not only becomes a cathode with a higher electric potential than that of the zinc itself, but also expands the area compared to the zinc anode, which prompts the anode elution of the exposed zinc. Eventually, the iron base material is exposed. At this time, the galvanized layer covered with the surrounding coating fails to serve as a sacrificial anode because the polarity is reversed with respect to the iron, and the valuable potential of the zinc plating surface accelerates the corrosion of the exposed iron matrix.

As the $\mathrm{pH}$ changes from neutral to acidic, the zinc corrosion rate increases. This is because the basic materials—such as zinc oxide, zinc hydroxide, and basic carbonate salts-constituting the protective coating on the zinc surface are neutralized in the acidic environment and disappear.

\subsection{Electrolytic Corrosion}

Leakage current can flow in a contaminated wet insulator. If this leakage current contains a DC component, electrolytic corrosion may occur [9]. The diameter of the pin may then be reduced and its mechanical strength weakened. A zinc sleeve-a sacrificial electrode-is sometimes inserted to protect the pin from this electromotive force [10].

\subsection{Crevice Corrosion}

Crevice corrosion is localized corrosion that occurs in the gap between a metal and non-metal. For an insulator, crevice corrosion occurs where the pin is in contact with the cement.

Figure 5 shows the pin parts of the insulator specimens subjected to external corrosion. The diameters of the pins for the inside of the cement, the beginning of the exposure, and the vicinity of the pinball are measured. Since the pin sample is cut in half, it can be measured smaller than the original diameter, but the relative change in the diameter according to the pin position can be identified. When visually observed, it can be seen that the corrosion of the exposed part is more advanced than that in the cement. It can be seen that the degree of corrosion slows down from the beginning of the exposed part to the pinball part. Similarly, the pin diameter at the inner and outer boundaries of cement was the smallest at $17.0 \mathrm{~mm}$ compared to the periphery. When severe crevice corrosion occurs, the middle of the pin gets extremely thin and may be broken.

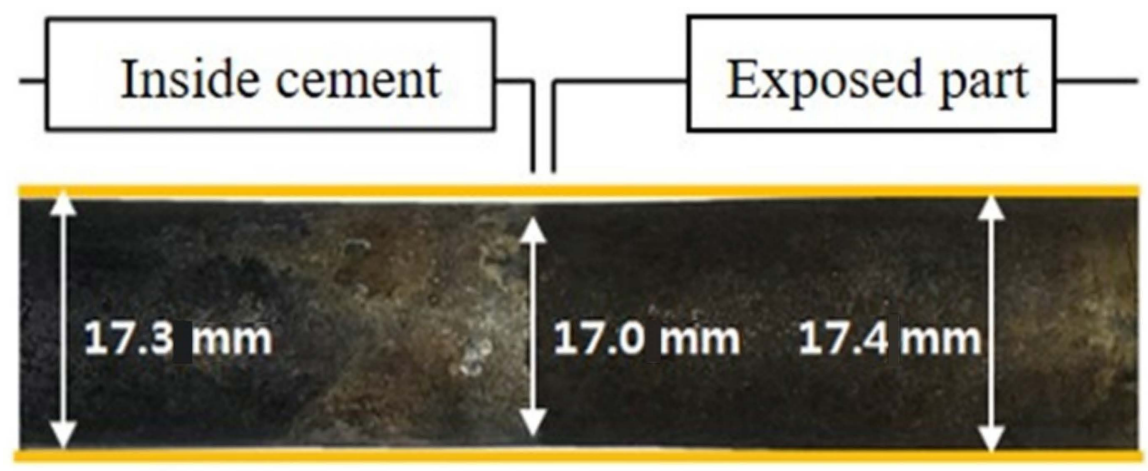

Figure 5. Pin position where crevice corrosion occurs.

\subsection{Effects of Corrosion}

When rust forms on connection parts, it becomes impossible to attach and detach porcelain insulators during maintenance. If a special load—such as typhoon, ice, snow, or earthquake-is applied, or flexibility is required for repair work, the connection part may break. As the service life increases, the cement inside the cap deteriorates, and the inside of the cap is exposed such that corrosion may occur. To prevent this, a zinc ring is sometimes installed between the porcelain and cap [11]. 
For the case of the pin, a rusted pin may expand and cause breakage of the porcelain. When crevice corrosion occurs at the interface between the cement and pin, the diameter of the pin decreases and, in the worst case, the connection is broken. Figure 5 shows the corrosion at the pin of a porcelain insulator and Figure $6 \mathrm{~b}$ shows a broken pin due to the severe crevice corrosion.

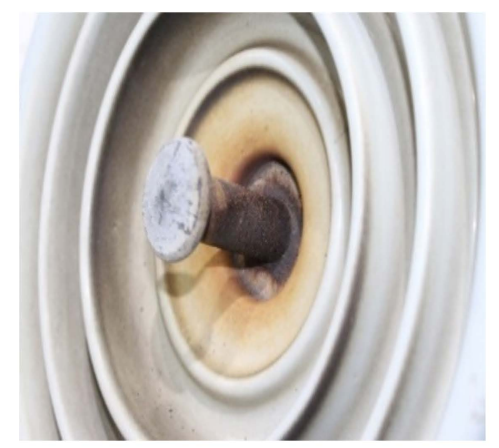

(a)

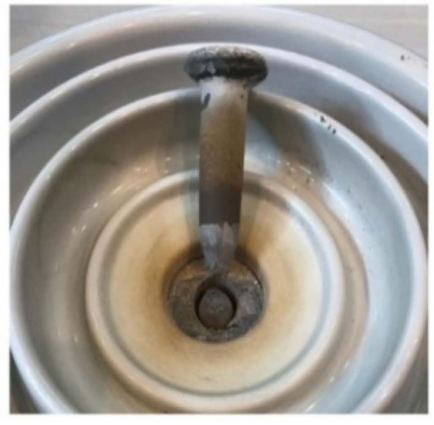

(b)

Figure 6. (a) Pin corrosion and (b) severe crevice corrosion.

\subsection{Geographical Dependence}

Figure 7 shows the corrosion rates of zinc at different thicknesses and environments. It is reported that repair or replacement is needed when rusting of the metal surface is at $5 \%$. For example, at a zinc thickness of $75 \mu \mathrm{m}$, the steal will last for approximately 56 years in industrial areas, or more than 100 years in the rural area [12-14]. It is known that corrosion is affected by sea salt and pollution. In coastal areas, $\mathrm{NaCl}$ accelerates corrosion and, in industrial areas, corrosive gases $\left(\mathrm{SO}_{2}, \mathrm{NO}_{\mathrm{x}}\right.$, and $\left.\mathrm{Co}\right)$ are released, which cause acid rain. Normal rainfall has a relatively low $\mathrm{pH}$ of 5.6 because of dissolved carbon dioxide. However, most rainfall is $\mathrm{pH}$ less than 5.6 due to $\mathrm{SO}_{\mathrm{x}}$ and $\mathrm{NO}_{\mathrm{x}}$. The strict definition of acid rain is rain with a $\mathrm{pH}$ lower than 5.6. However, rain is more commonly referred to as acid rain when the $\mathrm{pH}$ is 5 or more. In 2006, the average monthly $\mathrm{pH}$ values of rainfall in Gangneung, Daejeon, Daegu, Busan, and Ulsan were 5.52, 4.81, 5.61, 5.69, and 4.90, respectively [8-13].

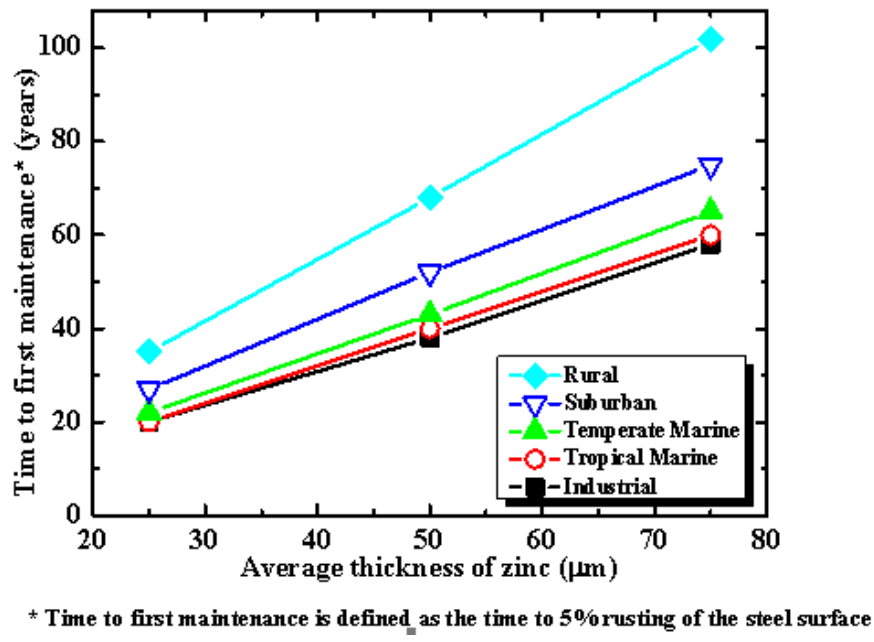

Figure 7. Corrosion rate of zinc in different environments.

Figure 8 shows the caps and pins of insulators gathered from Daejeon, Ulsan, and Busan. Although the average $\mathrm{pH}$ values of rainfall in Daejeon and Ulsan are similar, it is notable that rainfall in Ulsan is very acidic during the winter since Ulsan is an industrial city. The considerable progress of erosion found in Ulsan can be attributed to acid rain caused by pollutants- such as $\mathrm{SO}_{\mathrm{x}}$ and $\mathrm{NO}_{x}$ - from factories and automobile exhaust. Comparatively, the corrosion found in the insulators used in Busan 
was due to $\mathrm{NaCl}$, since Busan is a coastal city. From the images in Figure $8 \mathrm{~b}$ collected from the Ulsan site with rainfall having a $\mathrm{pH}$ of 4.90 is less rusted than the other two samples taken from Daejeon with a $\mathrm{pH}$ of 4.81 and Busan with a $\mathrm{pH}$ of 5.69. On the other hand, erosion is more pronounced on the Ulsan sample. Thus, $\mathrm{NaCl}$ causes less rust but more erosion. For the insulator used in Daegu for 48 years, there was substantial rust on one side of the cap and a smaller amount at the pin. This is due to the direction of wind flow. The contaminants will deposit on one side of the porcelain insulator [15]. Moreover, the direction of wind flow also decides the direction of corrosion propagation as observed in the previously mentioned sample.
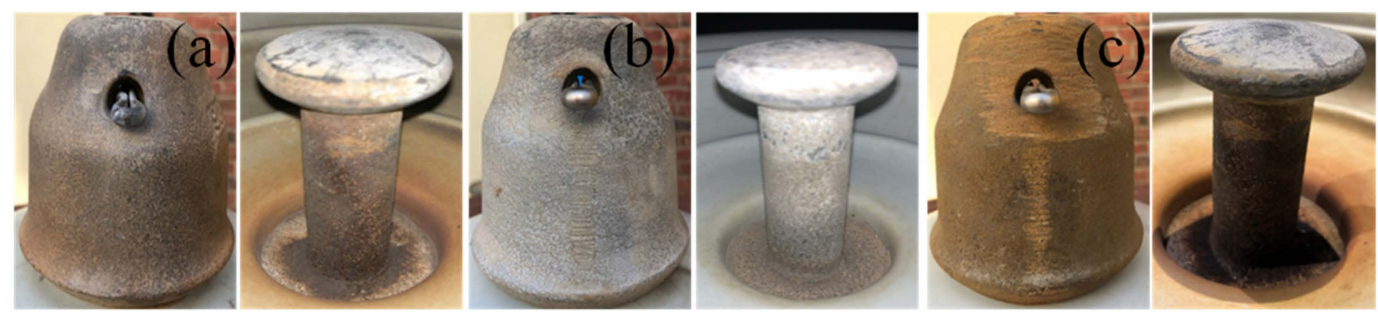

Figure 8. Pictures of pins and caps of porcelain insulators gathered from (a) Daejeon, (b) Ulsan, and (c) Busan. Each was used for 38 years.

\section{Conclusions}

This article focuses on corrosion in the porcelain insulator and its dependency on geographical conditions of the region. Different kinds of corrosion that occur in the pin and cap have been reported. The cap and pin of a porcelain insulator are made of iron. It is well known that, as time passes, iron rusts. The methods to prevent corrosion have been investigated. The investigation of porcelain insulators gathered from different regions in Korea used for different lengths of time shows that the geographical environment affects corrosion more than the served lifetime. The amount of acid rain and sea salt that causes rapid rusting is dependent on the geographical environment. Thus, when calculating the lifetime of porcelain insulators, the location where they are to be installed should be considered. Recently, new materials—such as PosMAC, which is a strong alloy made of magnesium, zinc, and aluminum-have been reported as being much more effective than zinc in preventing corrosion. Still, to prolong the lifetime of porcelain insulators, further study is required in which the application of new materials or use of a waterproof coating (in addition to the zinc coating) could be examined.

Author Contributions: T.K. contributed to this work in experiment planning, experiment measurements, data analysis and manuscript preparation. Y.-J.L. manuscript preparation. J.-W.W. contributed research sample preparation. S.S. contributed research sample preparation. I.-H.C. contributed research sample preparation. J.Y. contributed in experiment planning, data analysis. All authors have read and agreed to the published version of the manuscript.

Funding: This research was funded by Korea Electric Power Corporation R16TA29.

Conflicts of Interest: The authors declare no conflict of interest.

\section{References}

1. Choi, I.H.; Kim, T.K.; Yoon, Y.B.; Nguyen, T.; Yi, J. A Study on the Life-Time Assessment Ways and Various Failure Types of $154 \mathrm{kV}$ Porcelain Insulators Installed in South Korea. Trans. Electr. Electron. Mater. 2018, 19, 188-194. [CrossRef]

2. Luo, L.; Wang, L.; Mei, H.; Guan, Z. Corrosion mechanism and process of hardware of disc suspension type Insulators on $\pm 800 \mathrm{kV}$ transmission lines. IEEE Trans. Dielectr. Electr. Insul. 2016, 23, 339-349. [CrossRef]

3. Jiang, X.; Dong, B.; Hu, Q.; Yin, F. Effect of ultrasonic fog on AC flashover voltage of polluted porcelain and glass insulators. IEEE Trans. Dielectr. Electr. Insul. 2013, 20, 429-434. [CrossRef]

4. Luo, L.; Wang, L.; Guan, Z. Influence of pin corrosion on mechanical characteristic of UHVDC disc suspension insulators and solutions. IEEE Trans. Dielectr. Electr. Insul. 2015, 22, 2242-2251. 
5. Yang, Z.; Jiang, X.; Zhang, Z.; Zhang, D. Study on the influence rules of soluble contaminants on flashover voltage of disc suspension insulators. IEEE Trans. Dielectr. Electr. Insul. 2016, 23, 3523-3530. [CrossRef]

6. Yang, Z.; Jiang, X.; Zhang, Z.; Zhang, D.; Liu, Y. Electrical property of different types insulator string under typical pollution constituents. In Proceedings of the 2015 IEEE Conference on Electrical Insulation and Dielectric Phenomena (CEIDP), Ann Arbor, MI, USA, 18-21 October 2015; pp. 170-175.

7. Graedel, T.E. Corrosion Mechanisms for Zinc exposed to the atmosphere. J. Electrochem. Soc. 1989, 136, 193C-203C. [CrossRef]

8. Baker, A.C.; Farzaneh, M.; Gorur, R.S.; Gubanski, S.M.; Hill, R.J. Insulator Selection for AC Overhead Lines with Respect to Contamination. IEEE Trans. Power Deliv. 2009, 24, 1633-1641. [CrossRef]

9. Montoya, G.; Ramirez, I.; Montoya, J.I. Corelation among ESDD and NSDD and Leakage Current in Insulators. IEE Proc. Gener. Transm. Distrib. 2004, 151, 334-340. [CrossRef]

10. Roetheli, B.E.; Cox, G.L.; Literal, W.B. Effect of $\mathrm{pH}$ on the corrosion products and corrosion rate of zinc in oxygenated aqueous solutions. Met. Alloys 1932, 3, 73-76.

11. Cabtree, I.M.; Mackey, K.J.; Kito, K.; Naito, K.; Watanabe, A.; Irie, T. Studies on electrolytic corrosion of hardware of dc line insulators. IEEE Trans. Power Appar. Syst. 1985, 104, 645-654. [CrossRef]

12. Cherney, E.A.; Baker, A.C.; Kuffel, J.; Lodi, Z.; Phillips, A.; Powell, D.G.; Stewart, G.A. Evaluation of and replacement strategies for aged high voltage porcelain suspension-type insulators. IEEE Trans. Power Deliv. 2014, 29, 275-282. [CrossRef]

13. Daiming, Y.; Fanghui, Y.; Hongwei, M.; Liming, W. In-Situ Monitoring of Electrolytic Corrosion on the Caps of HVDC Insulators. IEEE Sens. J. 2018, 18, 8569-8577.

14. Luo, L.; Wang, L.; Guan, Z.; Mei, H.; Zhang, F.; Li, R.; Li, L. Research on the electrolytic corrosion problem of porcelain insulator's hardware on UHVDC transmission line. In Proceedings of the 2014 IEEE Electrical Insulation Conference (EIC), Philadelphia, PA, USA, 8-11 June 2014.

15. PosMac 3.0. Available online: https://www.posco.co.kr/homepage/docs/eng5/dn/product/info/posmac.pdf (accessed on 15 September 2018).

(C) 2020 by the authors. Licensee MDPI, Basel, Switzerland. This article is an open access article distributed under the terms and conditions of the Creative Commons Attribution (CC BY) license (http://creativecommons.org/licenses/by/4.0/). 